\title{
Dextrose Hydration May Promote Cisplatin-induced Nephrotoxicity in Rats: Gender-related Difference
}

\author{
Farzaneh Karimi ${ }^{1}$, Sayyedehnikta Kassaei ${ }^{1}$, Azar Baradaran ${ }^{1,2}$, Farzaneh Ashrafi, \\ Ardeshir Talebi ${ }^{1,2}$, Zahra Lak $^{1}$, Mehdi Nematbakhsh ${ }^{1,3,4},{ }^{*}$ \\ ${ }^{1}$ Water and Electrolytes Research Center, Isfahan University of Medical Sciences, Isfahan, Iran \\ ${ }^{2}$ Department of Clinical Pathology, Isfahan University of Medical Sciences, Isfahan, Iran \\ ${ }^{3}$ Department of Physiology, Isfahan University of Medical Sciences, Isfahan, Iran \\ ${ }^{4} \mathrm{Isfahan}^{\mathrm{MN}}$ Institute of Basic and Applied Sciences Research, Isfahan, Iran \\ *Corresponding author. E-mail: nematbakhsh@med.mui.ac.ir
}

Received date: Jul 31, 2018; Revised date: Nov 22, 2018; Accepted date: Nov 26, 2018

\section{Abstract}

B ACKGROUND: Cisplatin (CP) as an anticancer drug may affect the plasma glucose level while diabetic subjects are protected against $\mathrm{CP}$-induced nephrotoxicity. In the current study, the role of dextrose hydration during $\mathrm{CP}$ therapy on $\mathrm{CP}$-induced nephrotoxicity was evaluated.

METHODS: Sixty-nine male and female rats were divided into 12 groups. The rats were hydrated with $15 \mathrm{~mL} / \mathrm{kg}$ vehicle or different doses of $2 \%, 10 \%$ and $20 \%$ dextrose before and after $7.5 \mathrm{mg} / \mathrm{kg} \mathrm{CP}$ administration. One week later, the biochemical and kidney function markers, and histology finding were determined.

RESULTS: All the animals co-treated with CP and 20\% dextrose, were dead during one week of the experiment. Administration of $\mathrm{CP}$ alone increased kidney tissue damage score (KTDS) and kidney weight (KW). It also elevated the blood urea nitrogen (BUN) and BUN-creatineine ratio (BUN/Cr) levels in the serum. In addition, $\mathrm{CP}$ decreased body weight and creatinine $(\mathrm{Cr})$ clearance $(\mathrm{ClCr})$ significantly in both male and female rats $(p<0.05)$. However, $2 \%$ and $10 \%$ dextrose did not alter the mentioned parameters in male, but $10 \%$ dextrose supplement increased the serum levels of $\mathrm{BUN}, \mathrm{Cr}$ and $\mathrm{BUN} / \mathrm{Cr}$ ratio, $\mathrm{KW}$ and $\mathrm{KTDS}$ significantly in female rats $(p<0.05)$.

CONCLUSION: Our data suggest that not only do not support the nephro-protective role of dextrose hydration during CP therapy, the dextrose hydration can act as risk factor to promote $\mathrm{CP}$-induced nephrotoxicity in female rats. Prohibition of high carbohydrate (glucose) diet during CP therapy is recommended.

KEYWORDS: cisplatin, nephrotoxicity, dextrose, rat, gender

Indones Biomed J. 2019; 11(2): 136-44

\section{Introduction}

Cisplatin (CP) has been used widely in clinic for solid tumor chemotherapy; however one of the side effects of $\mathrm{CP}$ is nephrotoxicity which limits its clinical use. The CP-induced nephrotoxicity was reported to be gender related (1-4), and antioxidants supplements may attenuate the side effect of nephrotoxicity (1,5-9). The experimental findings also indicated that the sex hormone, estrogen, affects the CPinduced nephrotoxicity.(10-13) In addition, this female sex hormone may promote CP-induced nephrotoxicity (11) or limit the protective effect of antioxidant against $\mathrm{CP}$-induced kidney injury (13).

CP may decrease glucose uptake in ovarian cancer cell, and it disappears the membrane localization of glucose transporter 1.(14) In addition, CP itself may induce hyperglycemia and glucose intolerance (15), and this 
impairment maybe related to insulin secretion deficiency. (16) Previously, it was reported that in diabetic animals were protected against CP-induced nephrotoxicity.(17-20) Diabetes disturbs the active transport of proximal tubule and reduce $\mathrm{CP}$ accumulation in the tubule (21), therefore, it protects the kidney against $\mathrm{CP}$-induced nephrotoxicity. However, among the factors affecting CP-induced nephrotoxicity, the role of glucose is not well clear.

Usually, based on the treatment guideline, the candidate patients for $\mathrm{CP}$ therapy must be hydrated during $\mathrm{CP}$ administration.(22) If hyperglycemia is the main cause of kidney protection against $\mathrm{CP}$-induced nephrotoxicity in diabetic subjects, it is expected that the patients who hydrated with high glucose solution (instead saline) would be protected against $\mathrm{CP}$-induced nephrotoxicity. On the other hand, practically it is observed that many of the patients who are candidate for CP therapy have an appetite to eat cookie or high sweet diets during the $\mathrm{CP}$ administration time in the hospital.

Collectively, there are 2 facts. First, CP administration is accompanied with side effect of nephrotoxicity gender dependently.(1-4) Secondly, the diabetic subjects are protected against $\mathrm{CP}$-induced nephrotoxicity.(17-20) One explanation for this difference is related to the dose of glucose concentration which is different in normal and diabetic conditions. Therefore, one question was raised, is high dose of glucose uptake during CP therapy could protect the kidney against $\mathrm{CP}$-induced nephrotoxicity or not, and what is the role of gender? In order to answer these questions, male and female rats were subjected to hydrate with different doses of dextrose solution during CP therapy, and they were compared with control group.

\section{Methods}

The protocol of this research was considered and approved by the Ethics Committee of Isfahan University of Medical Sciences (IR.MUI.REC.1397.2.055).

\section{Drugs}

The $\mathrm{CP}$ and dextrose were purchased from Malan (Athens, Greece) and Shahid Ghazi Pharmaceutical Co (Tabriz, Iran).

\section{Experimental Groups}

This research was conducted on 69 male and female Wistar rats in 12 groups (6 groups of male and 6 groups of female rats). Group 1 and 7 (vehicle groups) were consisted of 5 male and 6 female rats. Eleven rats were subjected to 3 treatments. The first treatment of vehicle (saline, $15 \mathrm{~mL} /$ $\mathrm{kg}$, intraperitoneally) was applied at the beginning of experiment. The second treatment of vehicle $(0.5-1 \mathrm{~mL} / \mathrm{rat})$ was applied $60 \mathrm{~min}$ post the first treatment. Finally, the third treatment of vehicle (saline, $15 \mathrm{~mL} / \mathrm{kg}$, intraperitoneally) was applied $60 \mathrm{~min}$ post the second treatment.

Group 2 and 8 were the dextrose $10 \%$ groups, which were consisted of 5 male and 6 female rats. They received the same regimen as groups 1 and 7, except they were given dextrose $10 \%(15 \mathrm{~mL} / \mathrm{kg}$, intraperitoneally) instead of vehicle (saline) for the first and third treatments.

Group 3 and 9, or known as CP groups, were consisted of 5 male and 6 female rats, which received the same regimen as group 1 and 7, except they were given $\mathrm{CP}$ (7.5 $\mathrm{mg} / \mathrm{kg}$, intraperitoneally), instead of vehicle (saline) for the second treatment.

Group 4 and 10 , the $\mathrm{CP}+$ dextrose $2 \%$ groups, were consisted of 6 male and 6 female. These 12 rats were also subjected to 3 treatments. The first treatment of dextrose $2 \%(15 \mathrm{~mL} / \mathrm{kg}$, intraperitoneally) was applied at the beginning of experiment. The second treatment of CP $(7.5$ $\mathrm{mg} / \mathrm{kg}$, intraperitoneally) was applied $60 \mathrm{~min}$ post the first treatment, and the third treatment of dextrose $2 \%(15 \mathrm{~mL} /$ $\mathrm{kg}$, intraperitoneally) was applied $60 \mathrm{~min}$ post the second treatment.

Group 5 and 11, the $\mathrm{CP}+$ dextrose $10 \%$ groups, were consisted of 6 male and 6 female rats, which were treated just like groups 4 and 10, except they received $15 \mathrm{~mL} / \mathrm{kg}$ of dextrose $10 \%$ instead of dextrose $2 \%$ for the first and third treatments.

Group 6 and 12, CP + dextrose 20\% groups, were consisted of 5 male and 6 female rats, which were treated as groups 4 and 10 , except they received $15 \mathrm{~mL} / \mathrm{kg}$ of dextrose $20 \%$ instead dextrose $2 \%$ for the first and third treatments.

\section{Survival Time Determination}

The animals were kept in standard cages with free access to water and food. All the animals were observed continually (3-4 times a day) and weighted in the first and $8^{\text {th }}$ days of experiment. The mortality rate for each animal group was recorded daily.

\section{Urine, Blood and Kidney Tissue Samples Collections}

The remained survived animals until the $8^{\text {th }}$ day were subjected to place in metabolic cages for 5 hours before sacrifice for urine collection. The total amount of urine collection in each animal was measured precisely and reported as microliter per minute per gram kidney tissue. Then, blood samples were obtained and the animals 
sacrificed humanly. The kidneys were removed rapidly and weighted. The tissues were fixed in formalin $10 \%$ to perform histological investigation using hematoxylin and eosin (H\&E) staining. The kidney tissue damage score (KTDS) was recorded by two pathologist who were blinded to study protocol. The score was assigned from 1 to 4 based on intensity of tissue damage while zero was considered as normal.

\section{Biochemical Parameters Measurements}

The levels of blood urea nitrogen (BUN) and creatinine $(\mathrm{Cr})$, were determined using quantitative diagnostic kits (Pars Azmoon, Tehran, Iran). The malondialdehyde (MDA) levels in the serum and kidney tissue were measured by the manual method. The serum and kidney tissue levels of nitrite (stable nitric oxide (NO) metabolite) were measured using Griess method. The levels of sodium $(\mathrm{Na})$ in serum and urine were determined using flame photometer assay.

\section{Kidney Function Parameters Measurements}

The $\mathrm{Cr}$ clearance $(\mathrm{ClCr})$ was determined using clearance formula as; $\mathrm{ClCr}=\mathrm{UF} * \mathrm{UCr} / \mathrm{PCr}$ where $\mathrm{UF}, \mathrm{UCr}$ and $\mathrm{PCr}$ were assigned for urine flow rate, urine $\mathrm{Cr}$ concentration and serum level of $\mathrm{Cr}$. The $\mathrm{Na}$ filtration rates $(\mathrm{FNa})$ and $\mathrm{Na}$ excretion rate $(\mathrm{ENa})$ were calculated by $[\mathrm{ClCr} \mathrm{x}$ serum concentration of $\mathrm{Na}$ ] and [UF $\mathrm{x}$ urine concentration of $\mathrm{Na}$ ] respectively.

\section{Statistical Analysis}

Data were reported as mean \pm SEM. The ANOVA and Dunnet test as post hoc were applied for comparison between the groups. The survival time and KTDS between the groups were compared by non-parametric tests of KruskalWallis and Mann-Whitney U. The statistical $p$-value was significant when it was less than 0.05 .

\section{Results}

\section{Animal's Survival Time}

The data for animal's survival time are tabulated in Table 1 . The entire male (survival time $=4.8 \pm 0.4$ days) and female (survival time $=4.0 \pm 0.0$ days) animals treated with $\mathrm{CP}+$ extrose $20 \%$ expired during the experiment and no animals were survived for the last day of experiment (sacrifice day). Therefore no data were reported here for these groups. No animals were died in the control groups of male (groups 1-3) and female (groups 7-9) rats. However, 3 male and 2 female animals that treated with $\mathrm{CP}+$ dextrose $2 \%-10 \%$ were expired during the experiment before sacrifice day (Table 1).

\section{Body and Kidney Weights}

The body weight percentage change $(\Delta \mathrm{W} \%)$ and normalized kidney weight $(\mathrm{KW})$ in vehicle, dextrose $10 \%$ or $\mathrm{CP}$ alone (male's group 1-3 and female's group 7-9) treated groups were compared to determine the effect $\mathrm{CP}$ or dextrose alone administration (Table 2A). The results indicated that $\mathrm{CP}$ increased the absolute $\Delta \mathrm{W}$ and $\mathrm{KW}$ significantly $(p<0.05)$ in both genders.

The animals treated with $\mathrm{CP}$ alone also were compared with the animals co-treated with $\mathrm{CP}$ and dextrose (Figure 1A). Co-administration of $\mathrm{CP}$ and dextrose did not attenuate the $\mathrm{KW}$ when compared with $\mathrm{CP}$ alone treated group (Figure 1A). Instead, in the female rats, co-administration of $\mathrm{CP}$ and dextrose $10 \%$ not only attenuate the KW but also increased the KW $(1.36 \pm 0.16 \mathrm{~g})$ significantly when compared with CP alone $(0.94 \pm 0.04 \mathrm{~g})$ treated group $(p<0.05)$ (Figure 1A).

\section{Biochemical Parameters}

The serum levels of BUN, $\mathrm{Cr}$ and $\mathrm{BUN} / \mathrm{Cr}$ ratio in vehicle, dextrose $10 \%$ or CP alone treated groups (male's group 1-3 and female's group 7-9) were compared to determine the effect $\mathrm{CP}$ or dextrose alone administration (Table 2B). The results indicated that $\mathrm{CP}$ increased the above parameters (except the serum level of $\mathrm{Cr}$ in female) significantly $(p<0.05)$.

The animals treated with $\mathrm{CP}$ alone also were compared with the animals co-treated with $\mathrm{CP}$ and dextrose (Figure 1B). Co-treatment of $\mathrm{CP}$ and dextrose did not attenuate the serum level of $\mathrm{BUN}, \mathrm{Cr}$ and $\mathrm{BUN} / \mathrm{Cr}$ ratio in male. However, in female rats, the co-administration of $\mathrm{CP}$ and dextrose $10 \%$ increased the serum level of BUN $(92.4 \pm 35.9$ $\mathrm{mg} / \mathrm{dL} v s .28 .4 \pm 1.8 \mathrm{mg} / \mathrm{dL}, p<0.05), \mathrm{Cr}(1.6 \pm 0.4 \mathrm{mg} / \mathrm{dL} v s$. $0.75 \pm 0.05 \mathrm{mg} / \mathrm{dL}, p<0.05)$ and $\mathrm{BUN} / \mathrm{Cr}$ ratio $(52.7 \pm 7.3 v s$. $38.2 \pm 2.0, p<0.05)$ significantly) when compared with $\mathrm{CP}$ alone treated group.

The serum and kidney tissue levels of nitrite and MDA in vehicle, dextrose $10 \%$ or CP alone treated groups (male's group 1-3 and female's group 7-9) also were compared to determine the effect $\mathrm{CP}$ or dextrose alone administration (Table 2C). The results indicated that $\mathrm{CP}$ altered the serum and kidney levels of nitrite and the serum level of MDA significantly $(p<0.05)$ in male groups.

The animals treated with $\mathrm{CP}$ alone also were compared with the animals co-treated with $\mathrm{CP}$ and dextrose (Figure 1C). The serum and kidney tissue levels of MDA in male rats were not different statistically between $\mathrm{CP}$ alone treated 


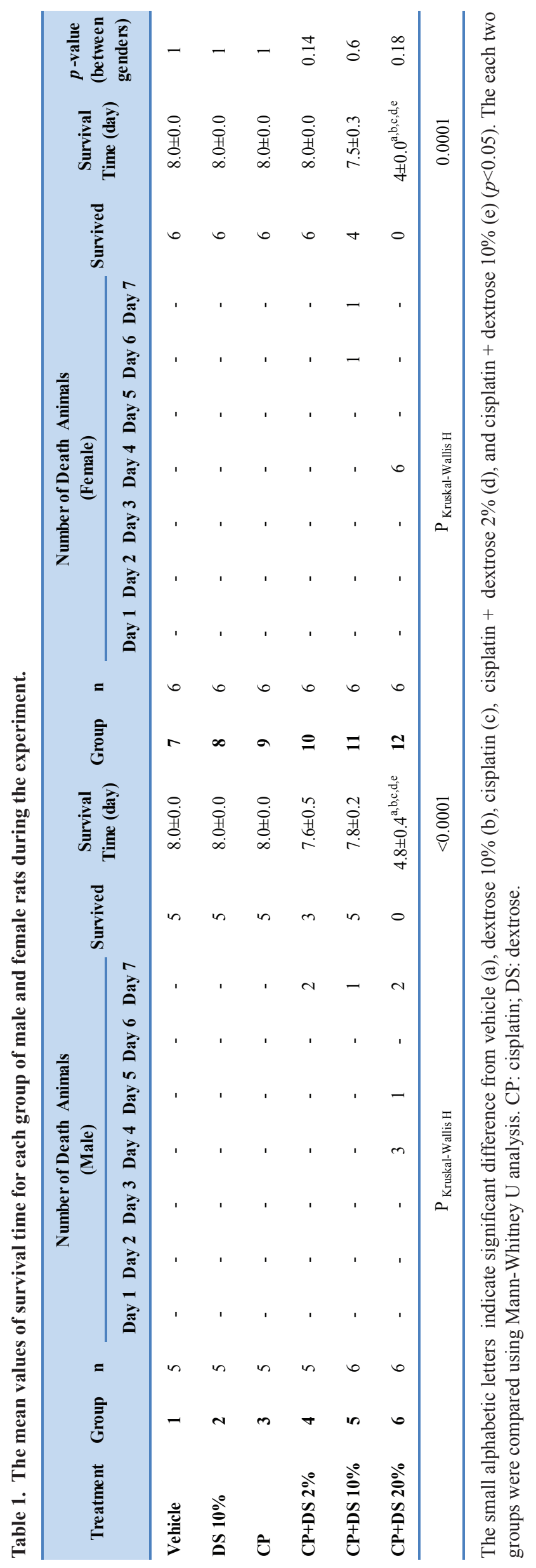


Table 2. The effects of dextrose $10 \%$ and $\mathrm{CP}$ administration against vehicle on body and kidney weight (A), serum levels of BUN, $\mathrm{Cr}$, BUN/Cr ratio (B), and serum and kidney levels of nitrite and MDA (C).

\begin{tabular}{|c|c|c|c|c|c|}
\hline Parameter & Gender & Vehicle & Dextrose $10 \%$ & $\mathbf{C P}$ & $P_{\text {ANOVA }}$ \\
\hline \multirow{2}{*}{$\Delta \mathrm{W}(\%)$} & Male & $-1.0 \pm 1.0$ & $3.7 \pm 1.0^{*}$ & $-19.0 \pm 1.2 *$ & $<0.0001$ \\
\hline & Female & $1.9 \pm 0.9$ & $-1.8 \pm 1.2$ & $-9.0 \pm 3.4 *$ & 0.008 \\
\hline \multirow{2}{*}{$\mathrm{KW}(\mathrm{g}) / 100 \mathrm{~g}$ BW } & Male & $0.68 \pm 0.02$ & $0.67 \pm 0.02$ & $1.06 \pm 0.04 *$ & $<0.0001$ \\
\hline & Female & $0.76 \pm 0.02$ & $0.83 \pm 0.02$ & $0.94 \pm 0.04 *$ & 0.002 \\
\hline Parameter & Gender & Vehicle & Dextrose $10 \%$ & $\mathbf{C P}$ & $P_{\text {ANOVA }}$ \\
\hline \multirow{2}{*}{ BUN (g/dL) } & Male & $17.94 \pm 0.6$ & $25.14 \pm 0.7$ & $43.1 \pm 6.6^{*}$ & 0.002 \\
\hline & Female & $20.48 \pm 1.14$ & $20.71 \pm 0.73$ & $28.4 \pm 1.8^{*}$ & 0.001 \\
\hline \multirow{2}{*}{$\mathrm{Cr}(\mathrm{g} / \mathrm{dL})$} & Male & $0.87 \pm 0.06$ & $0.65 \pm 0.03 *$ & $1.25 \pm 0.07 *$ & $<0.0001$ \\
\hline & Female & $0.72 \pm 0.02$ & $0.74 \pm 0.01$ & $0.75 \pm 0.05$ & 0.83 \\
\hline \multirow{2}{*}{$\mathrm{BUN} / \mathrm{Cr}$} & Male & $20.9 \pm 1.6$ & $38.7 \pm 1.9 *$ & $33.6 \pm 4.2^{*}$ & 0.002 \\
\hline & Female & $28.4 \pm 2.1$ & $27.9 \pm 1.4$ & $38.2 \pm 2.0^{*}$ & 0.002 \\
\hline Parameter & Gender & Vehicle & Dextrose $10 \%$ & $\mathbf{C P}$ & $P_{\text {ANOVA }}$ \\
\hline \multirow{2}{*}{ Serum Nitrite $(\mu \mathrm{mol} / \mathrm{L})$} & Male & $9.23 \pm 1.07$ & $11.43 \pm 0.82$ & $17.89 \pm 2.10^{*}$ & 0.003 \\
\hline & Female & $11.04 \pm 1.55$ & $8.43 \pm 0.67$ & $13.19 \pm 2.83$ & 0.24 \\
\hline \multirow{2}{*}{ Kidney Nitrite $(\mu \mathrm{mol} / \mathrm{g})$} & Male & $0.15 \pm 0.02$ & $0.19 \pm 0.01$ & $0.10 \pm 0.01 *$ & 0.024 \\
\hline & Female & $0.18 \pm 0.03$ & $0.18 \pm 0.01$ & $0.16 \pm 0.02$ & 0.85 \\
\hline \multirow{2}{*}{ Serum MDA $(\mu \mathrm{mol} / \mathrm{L})$} & Male & $0.19 \pm 0.17$ & $0.25 \pm 0.14$ & $1.91 \pm 0.89 *$ & 0.06 \\
\hline & Female & $2.31 \pm 0.47$ & $1.68 \pm 0.25$ & $3.63 \pm 1.26$ & 0.23 \\
\hline \multirow{2}{*}{ Kidney MDA (nmol/g) } & Male & $55.34 \pm 1.71$ & $72.96 \pm 15.04$ & $48.88 \pm 3.66$ & 0.19 \\
\hline & Female & $94.10 \pm 10.98$ & $92.63 \pm 21.15$ & $71.10 \pm 4.24$ & 0.44 \\
\hline
\end{tabular}

The $p$-value was obtained by ANOVA, and the star $\left(^{*}\right)$ indicates significant differences $(p<0.05)$ from vehicle group using Dunnet test. CP: cisplatin, $\Delta \mathrm{W}$; weight change, KW: kidney weight, BUN: blood urea nitrogen, $\mathrm{Cr}$ : creatinine.

group and co-treated of $\mathrm{CP}$ and dextrose groups. However, in female rats the serum and kidney tissues levels of MDA were decreased in co-treated of $\mathrm{CP}$ and dextrose groups when compared with $\mathrm{CP}$ alone treated rats (Figure 1C), but the decrease was significant for the serum level of MDA in co-treated group of CP and dextrose $2 \%(0.60 \pm 0.15 \mu \mathrm{mol} / \mathrm{L}$ $v s .3 .6 \pm 1.3 \mu \mathrm{mol} / \mathrm{L}, p<0.05)$, and the decrease for the kidney tissue level of MDA was significant in co-treated group of $\mathrm{CP}$ and dextrose $10 \%(37.6 \pm 1.4 \mathrm{nmol} / \mathrm{g}$ tissue $v s .71 .1 \pm 4.2$ $\mathrm{nmol} / \mathrm{g}$ tissue, $p<0.05)$.

The serum levels of nitrite decreased (significantly), and the tissue levels of nitrite were increased (insignificantly) in co-treated of $\mathrm{CP}$ and dextrose male rats when compared with $\mathrm{CP}$ alone treated group (Figure 1C). Such observation was not seen in female rats but co-treatment of $\mathrm{CP}$ and dextrose $2 \%$ increased the kidney tissue level of nitrite statistically $(p<0.05)$.

\section{Kidney Function Parameters}

The UF, ClCr, FNa, ENa and $\mathrm{Na}$ excretion fraction (\%) in vehicle, dextrose $10 \%$ or $\mathrm{CP}$ alone treated groups (male's group 1-3 and female's group 7-9) were compared to determine the effect $\mathrm{CP}$ or dextrose alone administration (Table 3A). The $\mathrm{ClCr}$ and $\mathrm{FNa}$ in both genders, $\mathrm{ENa}$ in female and $\mathrm{Na}$ excretion fraction (\%) in male were significantly different between $\mathrm{CP}$ treated rats and vehicle treated group $(p<0.05)$.

The animals treated with $\mathrm{CP}$ alone also were compared with the animals co-treated with $\mathrm{CP}$ and dextrose (Figure 2). The results of renal function markers; UF, $\mathrm{ClCr}, \mathrm{FNa}$, $\mathrm{ENa}$ and percentage of $\mathrm{Na}$ excretion fraction are presented in Figure 2. They are indicated that co-administration of CP and dextrose compared to $\mathrm{CP}$ alone did not alter the renal function markers neither in male nor in female rats. Actually in female, all the above markers in co-treated group of $\mathrm{CP}$ 

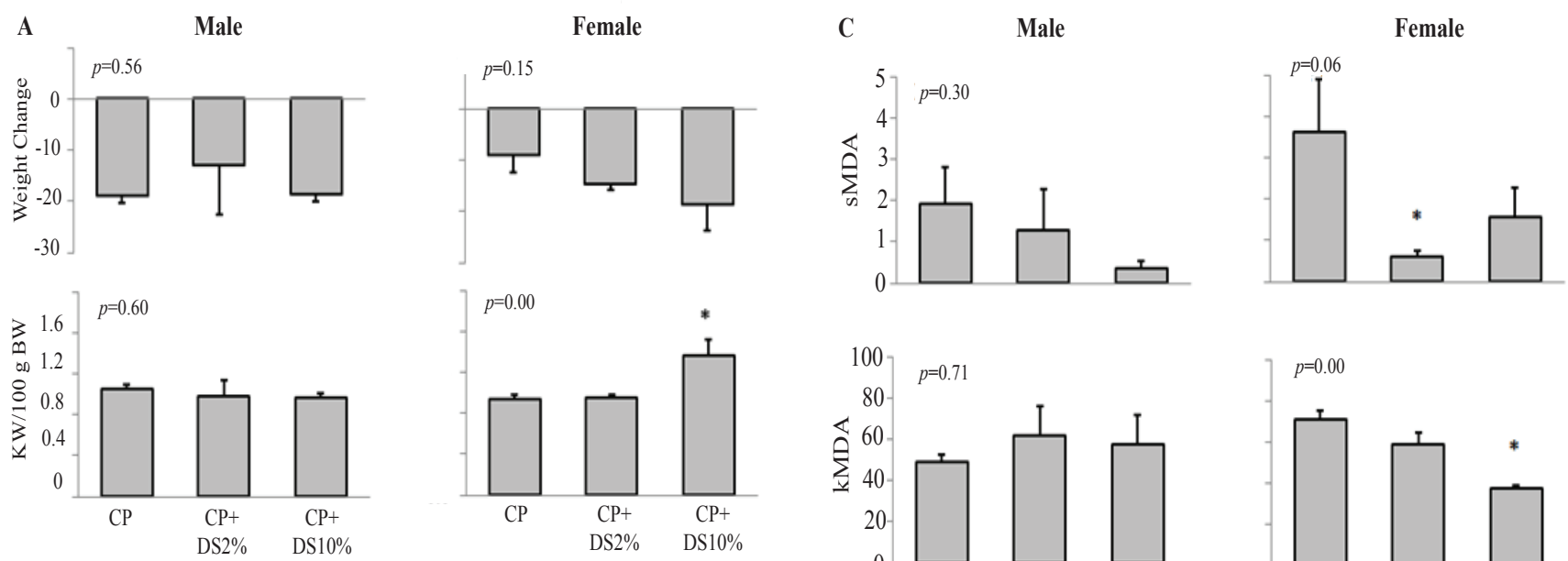

B
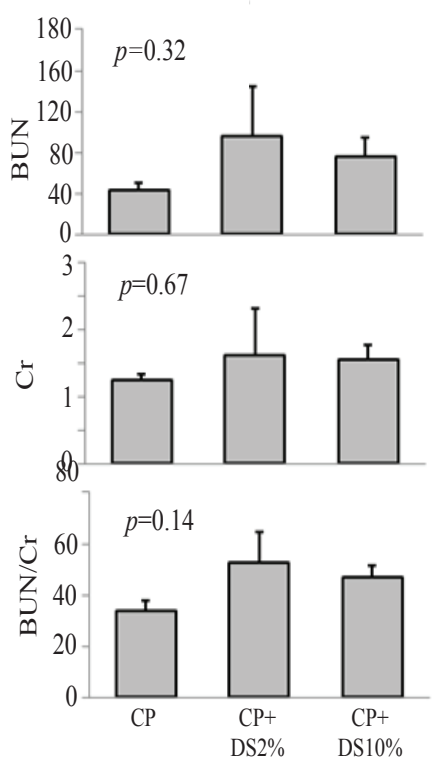
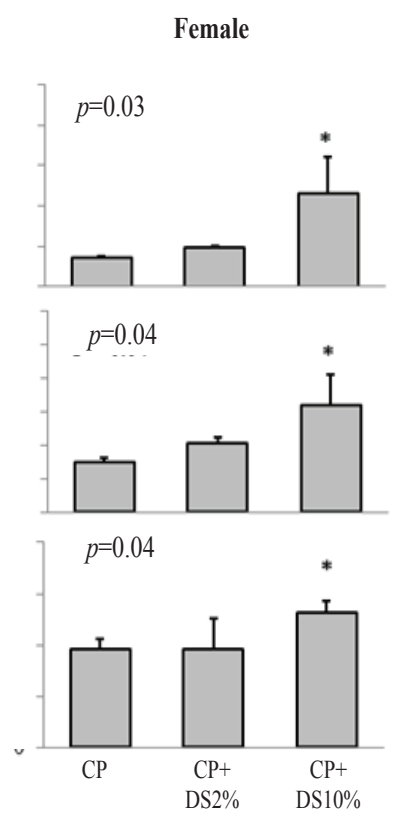
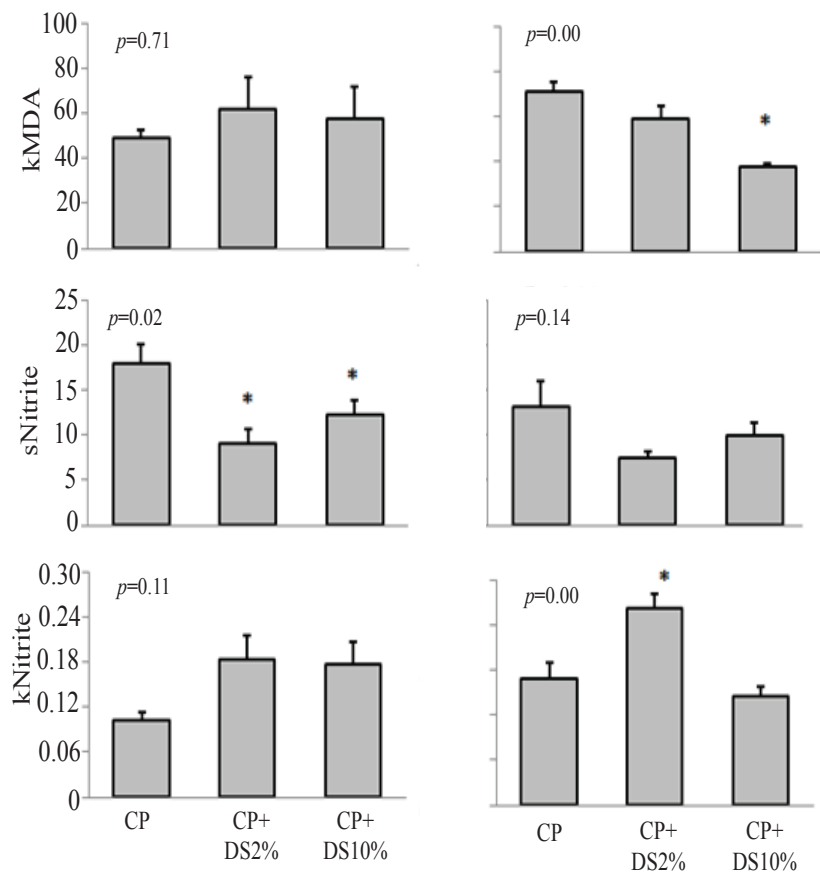

Figure 1. Characteristic difference between male and female rats of survived animals in the experimental groups. A: percentage of weight change (\%) and kidney weight $(\mathrm{KW})(\mathrm{g})$ per $100 \mathrm{~g}$ of body weight $(\mathrm{BW})$. B: serum levels of blood urea nitrogen (BUN) (mg/ $\mathrm{dL})$, creatinine $(\mathrm{Cr})(\mathrm{mg} / \mathrm{dL})$ and BUN/Cr ratio. C: serum $(\mu \mathrm{mol} / \mathrm{L})$ and kidney tissue $(\mu \mathrm{mol} / \mathrm{g}$ tissue) levels of malondealdehyde $(\mathrm{MDA})$ and nitrite for survived animals in the experimental groups. The $\mathrm{CP}, \mathrm{CP}+\mathrm{DS} 2 \%$ and $\mathrm{CP}+\mathrm{DS} 10 \%$ indicate the groups treated with cisplatin, cisplatin plus dextrose $2 \%$ and cisplatin plus dextrose $10 \%$, respectively. The $p$-value was obtained by ANOVA. The star $(*)$ indicates significant differences $(p<0.05)$ from CP using Dunnet test.

and dextrose $10 \%$ were decreased when compared with $\mathrm{CP}$ alone treated group, however these change were not statistically significant (Figure 2).

\section{Kidney Histology Findings}

The KTDS in vehicle, dextrose $10 \%$ or CP alone treated groups (male's group 1-3 and female's group 7-9) were compared to determine the effect $\mathrm{CP}$ or dextrose alone administration (Table $3 \mathrm{~B}$ ). The results indicated that $\mathrm{CP}$ increased the KTDS significantly $(p<0.05)$ in both genders.
The animals treated with CP alone also were compared with the animals co-treated with $\mathrm{CP}$ and dextrose (Figure 3 ). The KTDS did not alter in co-treated of CP and dextrose male rats compared to $\mathrm{CP}$ alone treated group, however in female rats, the KTDS was increased significantly in cotreated with $\mathrm{CP}$ and dextrose $10 \%$ group compared to $\mathrm{CP}$ alone treated group ( $3.3 \pm 0.2$ vs. $2.3 \pm 0.2 ; p<0.05)$. More tubular tissue damage was observed in female rats treated with CP and dextrose $10 \%$ compared to the CP alone treated animals. 
Table 3. The effects of dextrose $10 \%$ and cisplatin (CP) administration against vehicle on urine flow (UF), creatinine clearance $(\mathrm{ClCr})$, sodium (Na) filtration rate (FNa), Na excretion rate (ENa) and percentage of $\mathrm{Na}$ excretion fraction (\%) (A), and kidney tissue damage score (KTDS) (B).

\begin{tabular}{|c|c|c|c|c|c|}
\hline Parameter & Gender & Vehicle & Dextrose $10 \%$ & $\mathrm{CP}$ & $\mathbf{P}_{\text {ANOVA }}$ \\
\hline \multirow{2}{*}{$\mathrm{UF}(\mu \mathrm{L} / \mathrm{mim} / \mathrm{g})$} & Male & $2.9 \pm 0.7$ & $5.05 \pm 1.0$ & $4.50 \pm 0.8$ & 0.21 \\
\hline & Female & $5.3 \pm 0.7$ & $2.37 \pm 0.4^{*}$ & $4.01 \pm 1.0$ & 0.04 \\
\hline \multirow{2}{*}{$\mathrm{ClCr}(\mu \mathrm{L} / \mathrm{mim} / \mathrm{g})$} & Male & $732.6 \pm 125.1$ & $951.9 \pm 75.3$ & $197.8 \pm 26.6^{*}$ & $<0.0001$ \\
\hline & Female & $1148.3 \pm 144.6$ & $706.8 \pm 100.8^{*}$ & $510.1 \pm 142.0^{*}$ & 0.011 \\
\hline \multirow{2}{*}{$\mathrm{FNa}(\mu \mathrm{mole} / \mathrm{mim} / \mathrm{g})$} & Male & $120.6 \pm 22.9$ & $157.9 \pm 9.4$ & $33.8 \pm 4.8^{*}$ & $<0.0001$ \\
\hline & Female & $172.9 \pm 23.2$ & $115.9 \pm 15.4$ & $92.5 \pm 25.8^{*}$ & 0.05 \\
\hline \multirow{2}{*}{$\mathrm{ENa}(\mu \mathrm{mole} / \mathrm{mim} / \mathrm{g})$} & Male & $0.46 \pm 0.15$ & $1.16 \pm 0.14^{*}$ & $0.59 \pm 0.15$ & 0.014 \\
\hline & Female & $0.99 \pm 0.12$ & $0.35 \pm 0.08^{*}$ & $0.35 \pm 0.07 *$ & $<0.0001$ \\
\hline \multirow{2}{*}{ Na Excretion Fraction (\%) } & Male & $0.36 \pm 0.07$ & $0.74 \pm 0.09$ & $1.67 \pm 0.28^{*}$ & 0.001 \\
\hline & Female & $0.63 \pm 0.11$ & $0.41 \pm 0.18$ & $1.75 \pm 1.45$ & 0.5 \\
\hline Parameter & Gender & Vehicle & Dextrose $10 \%$ & $\mathbf{C P}$ & $\mathbf{P}_{\text {Kruskal-Wallis }}$ \\
\hline \multirow{2}{*}{ KTDS } & Male & $0.8 \pm 0.2$ & $0.6 \pm 0.2$ & $3.2 \pm 0.4^{*}$ & $<0.0001$ \\
\hline & Female & $1 \pm 0.3$ & $0.7 \pm 0.3$ & $2.3 \pm 0.2 *$ & $<0.0001$ \\
\hline
\end{tabular}

The $p$-value in part A was obtained by ANOVA, and the star $(*)$ indicates significant differences $(p<0.05)$ from vehicle group using Dunnet test. The $p$-value in part B was obtained Kruskal-Wallis, and the star $(*)$ indicates significant differences $(p<0.05)$ from vehicle group using Mann-Whitney U test. CP: cisplatin; UF: urine flow rate; ClCr: Creatinine clearance; FNa: sodium filtration rate; ENa: sodium excretion rate; KTDS: kidney tissue damage score.

\section{Discussion}

The purpose of this study was to determine the possible protective role of dextrose hydration during CP therapy against CP induced nephrotoxicity. Our hypothesis was rejected while dextrose promoted $\mathrm{CP}$-induced nephrotoxicity, and the major findings of this research revealed that dehydration with dextrose during CP therapy acts as risk factor to promote kidney toxicity.

No animals were survived when dextrose $20 \%$ was accompanied with $\mathrm{CP}$, possibly due to toxic effect of high dose of dextrose. The animals weight loss was observed in the all survived animals treated with $\mathrm{CP}$ which was expected
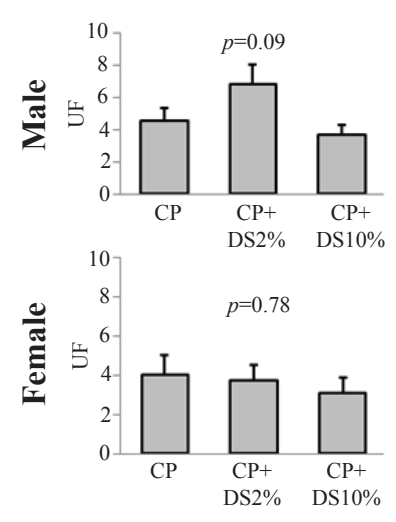
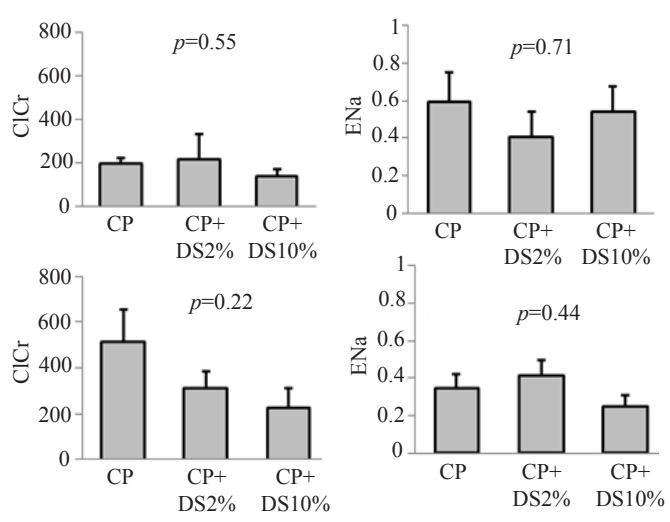
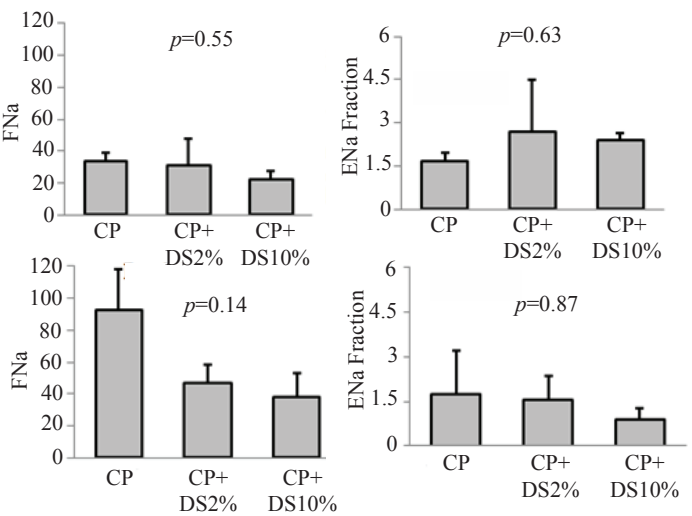

Figure 2. The urine flow (UF), creatinine clearance (ClCr), sodium (Na) filtration rate (FNa), Na excretion rate (ENa) and percentage of Na excretion fraction in cisplatin, cisplatin plus dextrose $2 \%$ and cisplatin plus dextrose $10 \%$ treated groups, respectively. The $p$-value was obtained by ANOVA. The star $(*)$ indicates significant differences $(p<0.05)$ from CP using Dunnet test. CP: cisplatin; DS: dextrose. The unit for $\mathrm{UF}=\mu \mathrm{L} / \mathrm{mim} / \mathrm{g}$ tissue, $\mathrm{ClCr}=\mu \mathrm{L} / \mathrm{mim} / \mathrm{g}$ tissue, $\mathrm{ENa}=\mu \mathrm{mol} / \mathrm{mim} / \mathrm{g}$ tissue, $\mathrm{FNa}=\mu \mathrm{mol} / \mathrm{mim} / \mathrm{g}$ tissue; $\mathrm{FNa}$ fraction= $\%$. 

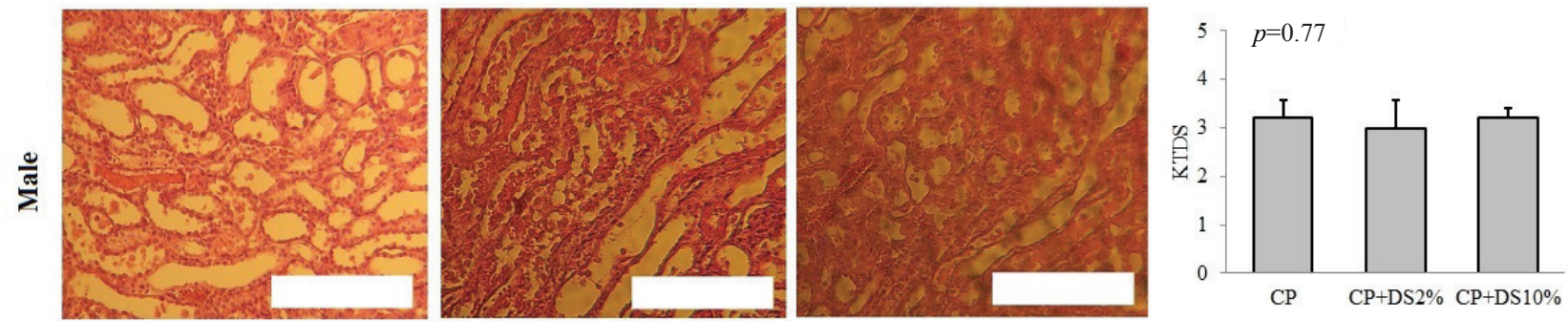

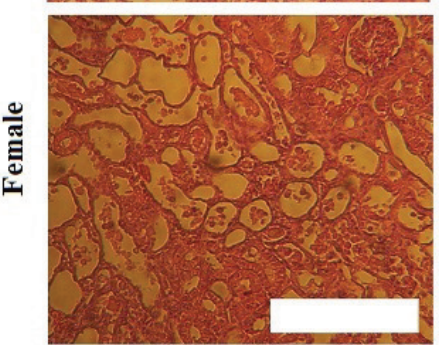

CP

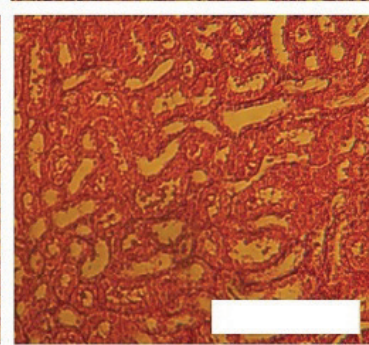

CP+DS2\%

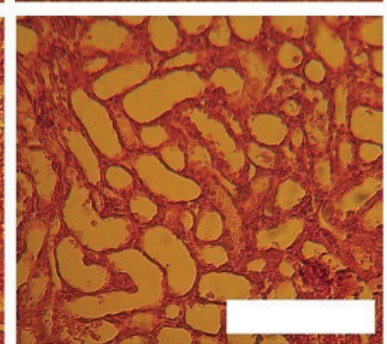

CP+DS10\%

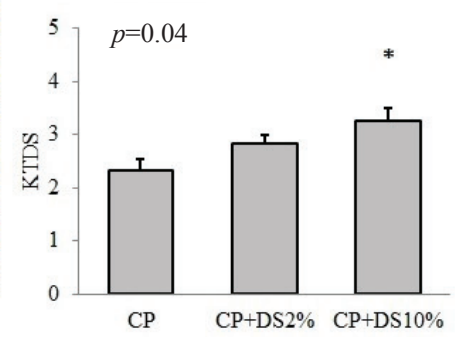

Fig 3. The kidney tissue damage score (KTDS) (right panel) for survived animal in the experimental groups. The $\mathrm{CP}, \mathrm{CP}+\mathrm{DS} 2 \%$ and $\mathrm{CP}+\mathrm{DS} 10 \%$ indicate the groups treated with cisplatin, cisplatin plus dextrose $2 \%$ and cisplatin plus dextrose $10 \%$, respectively. The $p$-value was obtained by Kruskal-Wallis test. The star indicates significant differences $(p<0.05)$ from CP using Mann-Whitney U test.White bar: $0.25 \mathrm{~mm} \times 1.0 \mathrm{~mm}$.

as observed in other studies.(1-4) In addition the elevations of the serum levels of BUN and $\mathrm{Cr}$ and $\mathrm{KW}$ are associated with increase of kidney damage after CP administration (4), and our results indicated that dextrose $10 \%$ elevated these parameters in female gender. It seems these alterations are related to the decrease of $\mathrm{ClCr}$ (or glomerular filtration rate) in female rats treated with $\mathrm{CP}$ and dextrose $10 \%$ (Figure 2). These findings in female rats also are in agreement with pathology data and KTDS (Figure 3).

It has been proposed that diabetes protects the kidneys against CP administration (18-20), and the degree of protection depends on degree of hyperglycemia. Previous study reported that the diabetic state could protect that kidney against CP-induced nephrotoxicity, and the kidney toxicity would be higher if the hyperglycemia was corrected by insulin.(20) The vacuolated cells, tubular dilation and necrosis-induced by $\mathrm{CP}$ administration in rat. However these tissue damages were attenuated in diabetic state.(20) One mechanism is related to kidney drug accumulation, because in diabetic state, the reduction of platinum accumulation in the kidney is occured.(23) One study demonstrated that hyperglaycemia reduction by insulin treatment in diabetic rats may not protect the kidney against CP-induced nephrotoxicity.(18) Therefore, it seems that an interaction between glucose concentration and $\mathrm{CP}$ exists as the membrane localization of glucose transporter 1 may disappear by $\mathrm{CP}$ therapy.(14)

In our study, it seems that the high dose of dextrose administration was toxic in $\mathrm{CP}$ treated rats, and possibly administration of dextrose induces insulin secretion in non-diabetics rats which causes platinium accumulation in renal cortex.(18) Therefore, accumulation of CP in kidney promotes nephrotoxicity as shown by increase in kidney weight and $\mathrm{Cr}$ level increase in dextrose treated rats. Other study demonstrated that the serum level of insulin was increased after 3 days post $\mathrm{CP}$ injection, and CP-induced hyperglycemia and glucosuria precede $\mathrm{CP}$ induced acute renal failure.(24)

\section{Conclusion}

Collectively, our data not only did not support the nephroprotective role of dextrose hydration during $\mathrm{CP}$ therapy but also indicated that dextrose diets during $\mathrm{CP}$ therapy act as risk factor to promote $\mathrm{CP}$-induced nephrotoxicity in female rats. Further studies are needed to find the exact mechanism.

\section{Acknowledgements}

This research was supported by Isfahan University of Medical Sciences (Grant \# 297054).

\section{References}

1. Nematbakhsh M, Pezeshki Z, Eshraghi Jazi F, Mazaheri B, Moeini $\mathrm{M}$, Safari T, et al. Cisplatin-induced nephrotoxicity; protective supplements and gender differences. Asian Pac J Cancer Prev. 2017; 18: 295-314. 
2. Nematbakhsh M, Ebrahimian S, Tooyserkani M, Eshraghi-Jazi F, Talebi A, Ashrafi F. Gender difference in Cisplatin-induced nephrotoxicity in a rat model: greater intensity of damage in male than female. Nephrourol Mon. 2013; 5: 818-21.

3. Eshraghi-Jazi F, Nematbakhsh M, Nasri H, Talebi A, Haghighi M, Pezeshki $\mathrm{Z}$, et al. The protective role of endogenous nitric oxide donor (L-arginine) in cisplatin-induced nephrotoxicity: Gender related differences in rat model. J Res Med Sci. 2011; 16:1389-96.

4. Haghighi M, Nematbakhsh M, Talebi A, Nasri H, Ashrafi F, Roshanaei $\mathrm{K}$, et al. The role of angiotensin II receptor 1 (AT1) blockade in cisplatin-induced nephrotoxicity in rats: gender-related differences. Renal Failure. 2012; 34: 1046-51.

5. Motamedi F, Nematbakhsh M, Monajemi R, Pezeshki Z, Talebi A, Zolfaghari B, et al. Effect of pomegranate flower extract on cisplatin-induced nephrotoxicity in rats. J Nephropathol. 2014; 3: 133-8.

6. Mazaheri S, Nematbakhsh M, Bahadorani M, Pezeshki Z, Talebi A, Ghannadi AR, et al. Effects of fennel essential oil on cisplatininduced nephrotoxicity in ovariectomized rats. Toxicol Int. 2013; 20: $138-45$.

7. Nematbakhsh M, Hajhashemi V, Ghannadi A, Talebi A, Nikahd M. Protective effects of the Morus alba L. leaf extracts on cisplatininduced nephrotoxicity in rat. Res Pharm Sci. 2013; 8: 71-7.

8. Nematbakhsh M, Ashrafi F, Safari T, Talebi A, Nasri H, Mortazavi M, et al. Administration of vitamin $\mathrm{E}$ and losartan as prophylaxes in cisplatin-induced nephrotoxicity model in rats. J Nephrol. 2012; 25: 410-7.

9. Hosseinian S, Khajavi Rad A, Hadjzadeh MA, Roshan NM, Havakhah $\mathrm{S}$, Shafiee $\mathrm{S}$. The protective effect of Nigella sativa against cisplatininduced nephrotoxicity in rats. Avicenna J Phytomed. 2016; 6: 4454.

10. Chen WY, Hsiao CH, Chen YC, Ho CH, Wang JJ, Hsing CH, et al. Cisplatin nephrotoxicity might have a sex difference. An analysis based on women's sex hormone changes. J Cancer. 2017; 8: 393944.

11. Pezeshki Z, Nematbakhsh M, Nasri H, Talebi A, Pilehvarian AA, Safari $\mathrm{T}$, et al. Evidence against protective role of sex hormone estrogen in Cisplatin-induced nephrotoxicity in ovarectomized rat model. Toxic Int. 2013; 20: 43-7.

12. Ghasemi M, Nematbakhsh M, Pezeshki Z, Soltani N, Moeini M, Talebi A. Nephroprotective effect of estrogen and progesterone combination on cisplatin-induced nephrotoxicity in ovariectomized female rats. Indian J Nephrol. 2016; 26: 167-75.
13. Nematbakhsh M, Pezeshki Z, Eshraghi-Jazi F, Ashrafi F, Nasri $\mathrm{H}$, Talebi A, et al. Vitamin E, vitamin C, or losartan is not nephroprotectant against cisplatin-induced nephrotoxicity in presence of estrogen in ovariectomized rat model. Int J Nephrol. 2012; 2012: 284896. doi: 10.1155/2012/284896.

14. Egawa-Takata T, Endo H, Fujita M, Ueda Y, Miyatake T, Okuyama H, et al. Early reduction of glucose uptake after cisplatin treatment is a marker of cisplatin sensitivity in ovarian cancer. Cancer Sci. 2010; 101: 2171-8.

15. Goldstein RS, Mayor GH, Rosenbaum RW, Hook JB, Santiago JV, Bond JT. Glucose intolerance following cis-platinum treatment in rats. Toxicology. 1982; 24: 273-80.

16. Goldstein RS, Mayor GH, Gingerich RL, Hook JB, Rosenbaum RW, Bond JT. The effects of cisplatin and other divalent platinum compounds on glucose metabolism and pancreatic endocrine function. Toxicol Appl Pharmacol. 1983; 69: 432-41.

17. Najjar TA, Saad SY. Cisplatin pharmacokinetics and its nephrotoxicity in diabetic rabbits. Chemotherapy. 2001; 47: 128-35.

18. Sarangarajan R, Cacini W. Early onset of cisplatin-induced nephrotoxicity in streptozotocin-diabetic rats treated with insulin. Basic Clin Pharmacol Toxicol. 2004; 95: 66-71.

19. Soltani N, Nematbakhsh M, Eshraghi-Jazi F, Talebi A, Ashrafi F. Effect of oral administration of magnesium on cisplatin-induced nephrotoxicity in normal and streptozocin-induced diabetic rats. Nephrourol Mon. 2013; 5: 884-90.

20. Scott LA, Madan E, Valentovic MA. Attenuation of cisplatin nephrotoxicity by streptozotocin-induced diabetes. Fundam Appl Toxicol. 1989; 12: 530-9.

21. da Silva Faria MC, Santos NA, Carvalho Rodrigues MA, Rodrigues JL, Barbosa Junior F, Santos AC. Effect of diabetes on biodistribution, nephrotoxicity and antitumor activity of cisplatin in mice. Chem-Biol Interact. 2015; 229: 119-31.

22. Duffy EA, Fitzgerald W, Boyle K, Rohatgi R. Nephrotoxicity: evidence in patients receiving cisplatin therapy. Clin $\mathrm{J}$ Oncol Nurs. 2018; 22: 175-83.

23. Sarangarajan R, Cacini W. Diabetes-induced protection from cisplatin nephrotoxicity is associated with impairment of energydependent uptake by renal cortex slices. Pharmacol Toxicol. 1997; 81: 197-8.

24. Portilla D, Li S, Nagothu KK, Megyesi J, Kaissling B, Schnackenberg L, et al. Metabolomic study of cisplatin-induced nephrotoxicity. Kidney Int. 2006; 69: 2194-204. 